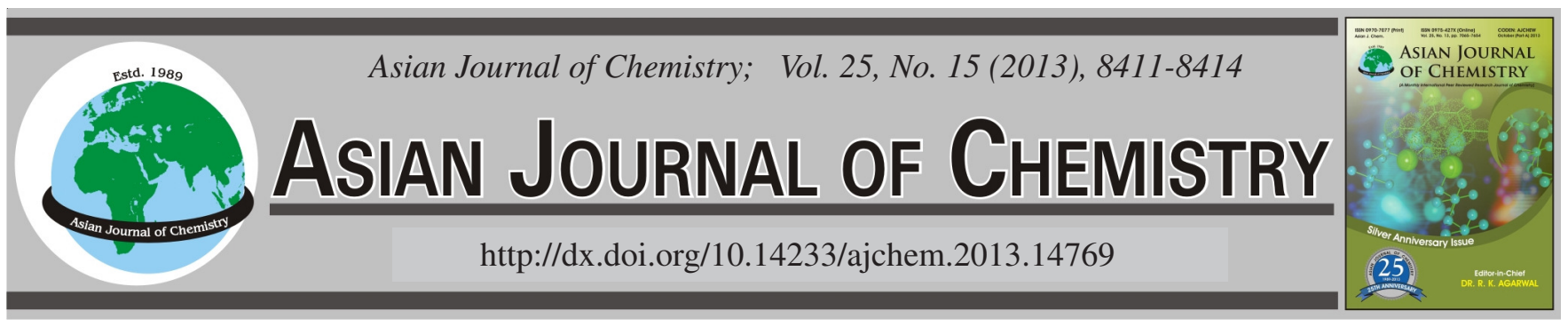

\title{
Synthesis, Crystal Structure and Luminescent Property of Cadmium(II) Complex Assembled by Sebacic Acid
}

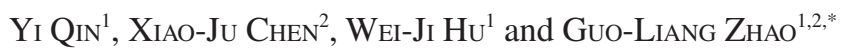

${ }^{1}$ Xingzhi College, Zhejiang Normal University, Jinhua 321004, P.R. China

${ }^{2}$ College of Chemistry and Life Science, Zhejiang Normal University, Jinhua 321004, P.R. China

*Corresponding author: Fax: +86 579 82282269; Tel: +86 579 82282061; E-mail: sky53@zjnu.cn

(Received: 3 November 2012;

Accepted: 23 August 2013)

AJC-13963

\begin{abstract}
A cadmium(II) complex $\left.\left[\mathrm{Cd}_{2} \mathrm{~L}_{2} \text { (phen }\right)_{4}\left(\mathrm{H}_{2} \mathrm{O}\right)\right] \cdot 5 \mathrm{H}_{2} \mathrm{O}(\mathbf{1})$ assembled by flexible ligand sebacic acid $\left(\mathrm{C}_{10} \mathrm{H}_{18} \mathrm{O}_{4}, \mathrm{H}_{2} \mathrm{~L}\right)$ and neutral N-based ligand 1,10-phenanthroline (phen), has been hydrothermally synthesized and characterized by elemental analysis, IR and TG. The singlecrystal X-ray diffraction studies demonstrated that the complex is crystallize in triclinic, $\mathrm{P}_{\mathrm{i}}$ space group, with $\mathrm{a}=1.15341(2), \mathrm{b}=1.34483(2)$, $\mathrm{c}=2.10931(3) \mathrm{nm}, \alpha=92.0120(10)^{\circ}, \beta=94.1770(10)^{\circ}, \gamma=91.8060(10)^{\circ}, \mathrm{V}=3.2592(3) \mathrm{nm}^{3}, \mathrm{Z}=2, \mathrm{C}_{68} \mathrm{H}_{76} \mathrm{~N}_{8} \mathrm{O}_{14} \mathrm{Cd}_{2}, \mathrm{M}_{\mathrm{r}}=1454.17, \mathrm{~F}_{(000)}$ $=1496, D_{c}=1.482 \mathrm{~g} / \mathrm{cm}^{-3}, \mu\left(M_{0} K_{\alpha}\right)=0.724 \mathrm{~mm}^{-1}$. The final $\mathrm{R}=0.0433$ and $\mathrm{wR}=0.1122$ for 11469 observed reflections with $\mathrm{I}>2 \sigma(\mathrm{I})$. The dual-nuclei bridge structure complex was formed by sebacic acid. The water dimer stay at the lattice space firmly through the hydrogen bonding. The luminescent property in solid state of complex 1 was also studied and discussed. CCDC: 877979.
\end{abstract}

Key Words: Sebacic acid, Flexible ligand, Cadmium complex, Crystal structure, Luminescent property.

\section{INTRODUCTION}

The design and synthesis of metal-organic compounds has attracted much attention due to their diverse topologies and potential applications in catalysis, molecular recognition, magnetism, electrochemisty, etc. ${ }^{1-5}$. With strong coordination ability and varieties of coordination modes, the rigid ligand is easy to form grid, brick wall, honeycomb and diamond-like shape network ${ }^{6-9}$, so a great deal of work were focus on the rigid ligand. Compared with the rigid ligand, the long flexible multi-function ligand tend to form unique interpenetrating and entangled architectures, such as catenanes and rotaxanes structure $^{10-12}$. At the same time, the flexible ligand is easy to adjust and modify, can easily bring in all kinds of coordination unit. Additionally, owing to the coordination modes can spread or concentration, rich variety of complexes based on flexible ligands can obtained. Therefore, the study on flexible ligands have made a great progress in recent years ${ }^{13-15}$. We have made great effort on the study of flexible carboxylic ligand complexes $^{16-18}$.

On the other hand, polynuclear $d^{10}$ metal complexes have attracted considerable interest recently because of their photoluminescent properties ${ }^{19-21}$. In this paper, one novel cadmium complex $\left.\left[\mathrm{Cd}_{2} \mathrm{~L}_{2} \text { (phen }\right)_{4}\left(\mathrm{H}_{2} \mathrm{O}\right)\right] \cdot 5 \mathrm{H}_{2} \mathrm{O}$ has been synthesized based on sebacic acid ligand and characterized by infrared spectroscopy, elemental analysis and X-ray crystallographi- cally. As a continuation of our search, the solid luminescent property was also studied and discussed.

\section{EXPERIMENTAL}

All the reagents and solvents used were of commercially available quality and without purified before using. FTIR spectra were recorded on a Nicolet NEXUS 670 FTIR spectrophotometer using $\mathrm{KBr}$ discs in the range of $4000-400 \mathrm{~cm}^{-1}$. Elemental analysis was performed on $\mathrm{C}, \mathrm{H}, \mathrm{N}$ elemental analyzer, Elementar Vario EL III. A Mettler Toledo thermal analyzer TGA/SDTA $851^{\mathrm{e}}$ was used to carry out the thermoanalytical analysis with a heating rate of $10{ }^{\circ} \mathrm{C} \mathrm{min}{ }^{-1}$ from $30-800{ }^{\circ} \mathrm{C}$ in air atomsphere. Fluorescent spectrum were recorded at room temperature on an Edinburgh FL920 phosphorimeter.

Synthesis of the complex: A mixture of $\mathrm{CdCl}_{2} \cdot 6 \mathrm{H}_{2} \mathrm{O}(1.0$ mmol, $0.2284 \mathrm{~g})$, sebacic acid (1.0 mmol, $0.2022 \mathrm{~g}), 1,10-$ phen (1.0 mmol, $0.1984 \mathrm{~g}), \mathrm{NaOH}(2.0 \mathrm{mmol}, 0.0800 \mathrm{~g})$ and $18 \mathrm{~mL}$ of $3: 1 \mathrm{H}_{2} \mathrm{O} /$ ethanol (v/v) was placed in a Parr Teflon lined stainless steel vessel $(25 \mathrm{~mL})$ and then the vessel was sealed and heated to $160{ }^{\circ} \mathrm{C}$ for $72 \mathrm{~h}$. After the reactant mixture was slowly cooled to room temperature over $3 \mathrm{~d}$, colourless block crystals were obtained and washed with water. Elemental analysis calcd. (\%) for $\mathrm{C}_{68} \mathrm{H}_{76} \mathrm{~N}_{8} \mathrm{O}_{14} \mathrm{Cd}_{2}$ : C, 56.10; $\mathrm{H}, 5.28$; N, 7.74. Found (\%): C 56.21, H 5.27, N 7.70. IR (KBr, $v_{\max }$, $\left.\mathrm{cm}^{-1}\right)$ : 3423(s), 3054(m), 2925(s), 2851(s), 1621(s), 1516(s), 
1461(m), 1425(s), 1406(s), 1303(m), 1240(m), 1189(m), 932(w), 854(s), 727(s), 679(w), 645(w).

X-Ray crystallography: The block crystal of the synthesized cadmium(II) complex sized in $0.218 \mathrm{~mm} \times 0.167 \mathrm{~mm} \times$ $0.088 \mathrm{~mm}$ was selected for structure analyses. The diffraction data was collected on a Bruker SMART APEX II CCD diffractomerer equipped with a graphite-momochromatized $\mathrm{MoK}_{\alpha}$ radiation $(\lambda=0.071073 \mathrm{~nm})$ at $296(2) \mathrm{K}$. Data intendity was corrected by Lorenta-polarization factors and empirical absorption. The structure was solved with direct methods and expanded with difference Fourier techniques. Except the hydrogen atoms on oxygen were located from the difference Fourier maps, the other hydrogen atoms were generated geometrically, the nonhydrogen atoms were refined anisotropically. All structure analysis and refinement were performed using SHELXS-9722 and SHELXL- $97^{23}$ program package, Experimental details for $\mathrm{X}$-ray data collection are presented in Table- 1 and the selected bond lengths and angles are listed in Table-2.

\begin{tabular}{|c|c|}
\hline \multicolumn{2}{|c|}{$\begin{array}{c}\text { TABLE-1 } \\
\text { CRYSTALLOGRAPHIC DATA FOR THE COMPLEX }\end{array}$} \\
\hline Empirical formula & $\mathrm{C}_{68} \mathrm{H}_{76} \mathrm{~N}_{8} \mathrm{O}_{14} \mathrm{Cd}_{2}$ \\
\hline Formula weight & 1454.17 \\
\hline Temperature (K) & $296(2)$ \\
\hline Wavelength (nm) & 0.071073 \\
\hline Crystal system & Triclinic \\
\hline Space group & $\mathrm{P}_{\mathrm{i}}$ \\
\hline $\mathrm{a}(\mathrm{nm})$ & $1.15341(2)$ \\
\hline $\mathrm{b}(\mathrm{nm})$ & $1.34483(2)$ \\
\hline $\mathrm{c}(\mathrm{nm})$ & $2.10931(3)$ \\
\hline$\alpha\left({ }^{\circ}\right)$ & $92.0120(10)$ \\
\hline$\alpha\left({ }^{\circ}\right)$ & $94.1770(10)$ \\
\hline$\gamma\left({ }^{\circ}\right)$ & $91.8060(10)$ \\
\hline $\mathrm{V}\left(\mathrm{nm}^{3}\right)$ & $3.25923(9)$ \\
\hline $\mathrm{Z}$ & 2 \\
\hline $\mathrm{D}_{\mathrm{c}}\left(\mathrm{g} \mathrm{cm}^{-3}\right)$ & 1.482 \\
\hline Absorption coefficient $\left(\mathrm{mm}^{-1}\right)$ & 0.724 \\
\hline $\mathrm{F}_{(000)}$ & 1496 \\
\hline Crystal size $(\mathrm{mm})$ & $0.202 \times 0.192 \times 0.168$ \\
\hline Theta range for data collection $\left({ }^{\circ}\right)$ & 0.97 to 25.00 \\
\hline Limiting indices & $\begin{array}{l}-13 \Leftarrow \mathrm{h} \Leftarrow 13,-15 \Leftarrow \mathrm{k} \Leftarrow 15, \\
-25 \Leftarrow 1 \Leftarrow 25\end{array}$ \\
\hline Reflections collected/unique & $44986 / 11469\left[\mathrm{R}_{\text {(int) }}=0.0411\right]$ \\
\hline Completeness to theta $=27.52(\%)$ & 99.9 \\
\hline Max. and min. transmission & 0.938 and 0.865 \\
\hline Refinement method & Full-matrix least-squares on $\mathrm{F}^{2}$ \\
\hline Data/restraints/parameters & $11469 / 2 / 828$ \\
\hline Goodness-of-fit on $\mathrm{F}^{2}$ & 1.098 \\
\hline Final $R$ indices $[\mathrm{I}>2 \sigma(\mathrm{I})]$ & $\mathrm{R}_{1}=0.0433, \mathrm{wR}_{2}=0.1122$ \\
\hline $\mathrm{R}$ indices (all data) & $\mathrm{R}_{1}=0.0631, \mathrm{wR}_{2}=0.1240$ \\
\hline Largest diff. peak and hole $\left(\mathrm{e} \mathrm{nm}^{-3}\right)$ & 771 and -568 \\
\hline
\end{tabular}

\section{RESULTS AND DISCUSSION}

IR spectrum: For the IR spectrum of the present cadmium complex, there is a broad strong peak observed at near 3423 $\mathrm{cm}^{-1}$, which corresponds to the stretching vibrations of $\mathrm{O}-\mathrm{H}$ of water molecules. The attendance of broad bond at 3054 $\mathrm{cm}^{-1}$ indicating the existance of hydrogen bonds between water. The complex shows the typical anti-symmetric $\left(1621 \mathrm{~cm}^{-1}\right)$ and symmetric $\left(1425 \mathrm{~cm}^{-1}\right)$ stretching bands of carboxylate groups. The absence of the characteristic bond around $1700 \mathrm{~cm}^{-1}$
TABLE-2

SELECTED BOND LENGTHS (nm) AND ANGLES $\left(^{\circ}\right)$

\begin{tabular}{cccc}
\hline Bond & Length & Bond & Length \\
\hline $\mathrm{Cd}(1)-\mathrm{O}(5) 2.995(4)$ & $0.2285(3)$ & $\mathrm{Cd}(2)-\mathrm{O}(1 \mathrm{~W})$ & $0.2344(3)$ \\
$\mathrm{Cd}(1)-\mathrm{O}(2) 2.995(4)$ & $0.2322(4)$ & $\mathrm{Cd}(2)-\mathrm{N}(5)$ & $0.2373(3)$ \\
$\mathrm{Cd}(1)-\mathrm{N}(4) 2.578(3)$ & $0.2423(3)$ & $\mathrm{Cd}(2)-\mathrm{N}(7)$ & $0.2386(3)$ \\
$\mathrm{Cd}(1)-\mathrm{N}(2)$ & $0.2427(3)$ & $\mathrm{Cd}(2)-\mathrm{N}(8)$ & $0.2388(4)$ \\
$\mathrm{Cd}(1)-\mathrm{N}(3)$ & $0.2436(3)$ & $\mathrm{Cd}(2)-\mathrm{O}\left(4^{\prime}\right)$ & $0.2406(15)$ \\
$\mathrm{Cd}(1)-\mathrm{N}(1)$ & $0.2451(3)$ & $\mathrm{Cd}(2)-\mathrm{N}(6)$ & $0.2437(3)$ \\
$\mathrm{Cd}(2)-\mathrm{O}(4)$ & $0.2307(10)$ & - & - \\
\hline Angle & $\left({ }^{\circ}\right)$ & $\mathrm{Angle}$ & $\left({ }^{\circ}\right)$ \\
\hline $\mathrm{O}(5)-\mathrm{Cd}(1)-\mathrm{O}(2)$ & $90.72(12)$ & $\mathrm{O}(4)-\mathrm{Cd}(2)-\mathrm{N}(7)$ & $85.8(3)$ \\
$\mathrm{O}(5)-\mathrm{Cd}(1)-\mathrm{N}(4)$ & $166.78(10)$ & $\mathrm{O}(1 \mathrm{~W})-\mathrm{Cd}(2)-\mathrm{N}(7)$ & $95.03(12)$ \\
$\mathrm{O}(2)-\mathrm{Cd}(1)-\mathrm{N}(4)$ & $94.36(12)$ & $\mathrm{N}(5)-\mathrm{Cd}(2)-\mathrm{N}(7)$ & $152.63(13)$ \\
$\mathrm{O}(5)-\mathrm{Cd}(1)-\mathrm{N}(2)$ & $90.33(11)$ & $\mathrm{O}(4)-\mathrm{Cd}(2)-\mathrm{N}(8)$ & $110.2(3)$ \\
$\mathrm{O}(2)-\mathrm{Cd}(1)-\mathrm{N}(2)$ & $166.26(12)$ & $\mathrm{O}(1 \mathrm{~W})-\mathrm{Cd}(2)-\mathrm{N}(8)$ & $161.08(12)$ \\
$\mathrm{N}(4)-\mathrm{Cd}(1)-\mathrm{N}(2)$ & $87.62(10)$ & $\mathrm{N}(5)-\mathrm{Cd}(2)-\mathrm{N}(8)$ & $94.10(12)$ \\
$\mathrm{O}(5)-\mathrm{Cd}(1)-\mathrm{N}(3)$ & $124.48(11)$ & $\mathrm{N}(7)-\mathrm{Cd}(2)-\mathrm{N}(8)$ & $69.70(12)$ \\
$\mathrm{O}(2)-\mathrm{Cd}(1)-\mathrm{N}(3)$ & $81.50(12)$ & $\mathrm{O}(1 \mathrm{~W})-\mathrm{Cd}(2)-\mathrm{O}\left(4^{\prime}\right)$ & $91.4(3)$ \\
$\mathrm{N}(4)-\mathrm{Cd}(1)-\mathrm{N}(3)$ & $68.44(10)$ & $\mathrm{N}(5)-\mathrm{Cd}(2)-\mathrm{O}\left(4^{\prime}\right)$ & $124.8(4)$ \\
$\mathrm{N}(2)-\mathrm{Cd}(1)-\mathrm{N}(3)$ & $86.62(10)$ & $\mathrm{N}(7)-\mathrm{Cd}(2)-\mathrm{O}\left(4^{\prime}\right)$ & $80.2(4)$ \\
$\mathrm{O}(5)-\mathrm{Cd}(1)-\mathrm{N}(1)$ & $79.62(11)$ & $\mathrm{N}(8)-\mathrm{Cd}(2)-\mathrm{O}\left(4^{\prime}\right)$ & $96.7(3)$ \\
$\mathrm{O}(2)-\mathrm{Cd}(1)-\mathrm{N}(1)$ & $125.30(12)$ & $\mathrm{O}(4)-\mathrm{Cd}(2)-\mathrm{N}(6)$ & $156.6(2)$ \\
$\mathrm{N}(4)-\mathrm{Cd}(1)-\mathrm{N}(1)$ & $87.50(10)$ & $\mathrm{O}(1 \mathrm{~W})-\mathrm{Cd}(2)-\mathrm{N}(6)$ & $79.52(12)$ \\
$\mathrm{N}(2)-\mathrm{Cd}(1)-\mathrm{N}(1)$ & $68.33(10)$ & $\mathrm{N}(5)-\mathrm{Cd}(2)-\mathrm{N}(6)$ & $69.41(12)$ \\
$\mathrm{N}(3)-\mathrm{Cd}(1)-\mathrm{N}(1)$ & $146.18(11)$ & $\mathrm{N}(7)-\mathrm{Cd}(2)-\mathrm{N}(6)$ & $87.69(11)$ \\
$\mathrm{O}(4)-\mathrm{Cd}(2)-\mathrm{O}(1 \mathrm{~W})$ & $78.7(3)$ & $\mathrm{N}(8)-\mathrm{Cd}(2)-\mathrm{N}(6)$ & $88.48(11)$ \\
$\mathrm{O}(4)-\mathrm{Cd}(2)-\mathrm{N}(5)$ & $121.1(3)$ & $\mathrm{O}\left(4^{\prime}\right)-\mathrm{Cd}(2)-\mathrm{N}(6)$ & $164.2(4)$ \\
$\mathrm{O}(1 \mathrm{~W})-\mathrm{Cd}(2)-\mathrm{N}(5)$ & $95.28(12)$ & & - \\
\hline & & & \\
\hline
\end{tabular}

attributed to the protonated carboxylic group indicate that the present deprotonation of $\mathrm{H}_{2} \mathrm{~L}$ ligand. In addition, the peak at about $645 \mathrm{~cm}^{-1}$ is associated with the coordinated water.

Structural description: The crystal structure of the present cadmium complex is shown in Fig. 1 (three $\mathrm{O}$ atoms $(\mathrm{O} 1, \mathrm{O} 3, \mathrm{O} 4)$ and three $\mathrm{C}$ atoms $(\mathrm{C} 3, \mathrm{C} 8, \mathrm{C} 9)$ are disorder, in order to make it clear, we don't show it). Which reveals that the complex crystallizes in $\mathrm{P}_{\mathrm{i}}$ space group. Each asymmetric unit consists of two independent $\mathrm{Cd}(\mathrm{II})$, two $\mathrm{L}^{2-}$ ligand, four phen, one crystaled water and five free water. This dual-nuclei was bridged by one sebacic acid $\left(\mathrm{L}^{2-}\right)$ ligand. Both $\mathrm{Cd}(1)$ and $\mathrm{Cd}(2)$ have hexacoordinated octahedral coordination fashion and in similar coordination environment. $\mathrm{Cd}(1)$ atom is coordinated with two $\mathrm{O}$ atoms from two different $\mathrm{L}^{2-}$ ligand $(\mathrm{Cd} 1-\mathrm{O}$ $0.2323(3)$ and $0.2285(3) \mathrm{nm}$ ) and four $\mathrm{N}$ donor of two independent phen ligand (Cd1-N 0.2423(3)-0.2451(3) nm). While $\mathrm{Cd}(2)$ is coordinated by one carboxylate oxygen atom from $\mathrm{L}_{2}^{-}$ligand, four $\mathrm{N}$ from two phen ligand (Cd2-N 0.2373(3)$0.2437(3) \mathrm{nm}$ ) and one water (Cd2-O1W 0.2344(3) nm), which is similar to the reported complex ${ }^{24}$. The $\mathrm{O}-\mathrm{Cd}-\mathrm{N}$ angles range from $79.62(11)-166.26(12)^{\circ}$ and $\mathrm{N}-\mathrm{Cd}-\mathrm{N}$ angles range from 68.33(10)-152.63(13) ${ }^{\circ}$. The selected important bond parameters are given in Table- 1 .

Significantly, hydrogen bonding interactions play vital role in the assembly of supramolecular architectures, there are plentiful hydrogen bonds among the water (Table-2). Which link the adjacent four molecules forming a two-fold 1D corrugated chain with non-interpenetrated along the $b$ axis (Fig. 2). The mode of connection is depicted in Fig. 3. Hydrogen-bonding association generates a cyclic 4- and 7-membered rings consisting of carboxyl and water centers (Table-3). These rings make the molecules running along $\mathrm{b}$ axi direction to form 


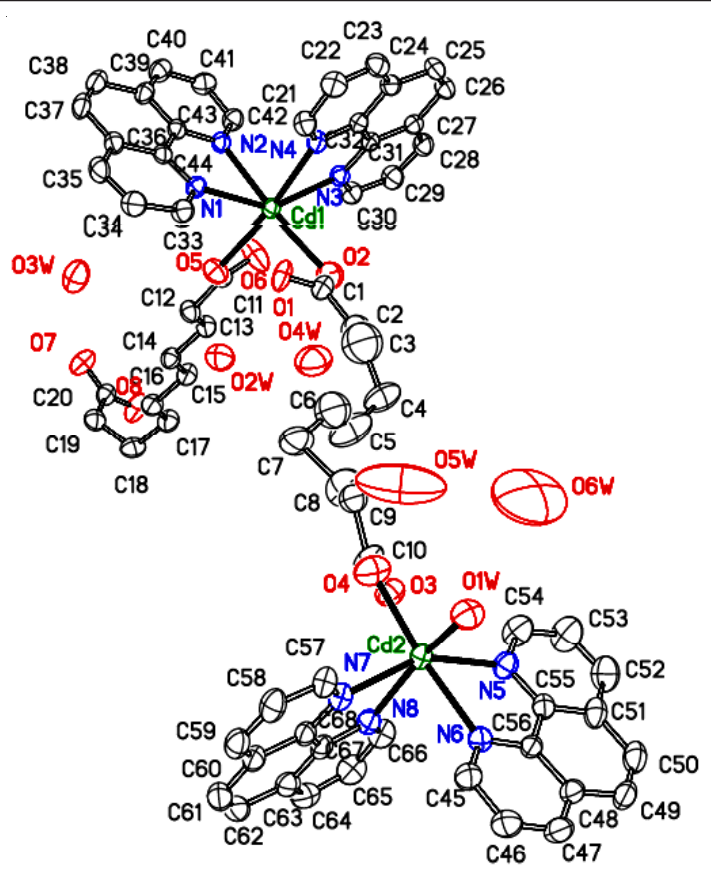

Fig. 1. Thermal eclipse diagram of the nonsymmetrical unit of present $\mathrm{Cd}(\mathrm{II})$ complex with ellipsoids at $30 \%$ probability and the hydrogen atoms are omitted

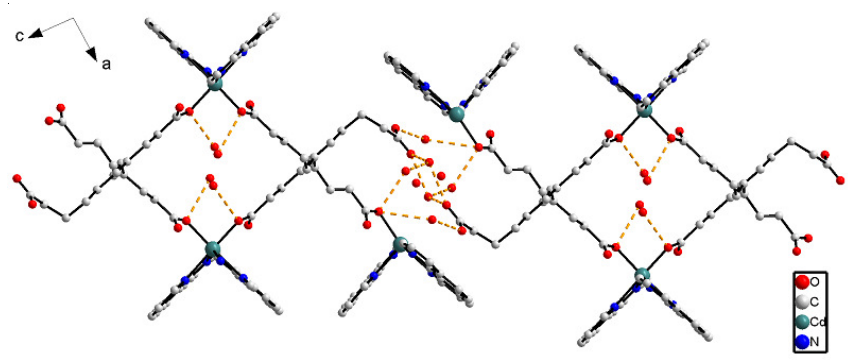

Fig. 2. 1D chain formed by hydrogen-bonding interactions in Cd(II) complex

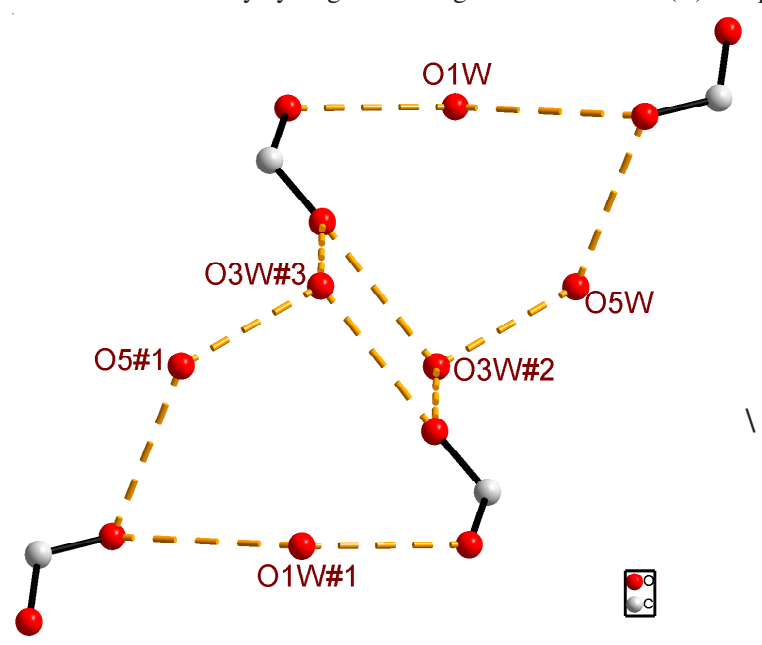

Fig. 3. Hydrogen-bonded model of the water molecules and carboxylic anions symmetry codes: \#1 2-x, 3-y, 2-z; \#2 -1+ x, 1+y, 1+z; \#3 3$\mathrm{x}, 1-\mathrm{y}, 1-\mathrm{z}$

a 1D corrugated supramolecular morphology, which can be described as O1W linking the adjacent carboxyl oxygens by hydrogen-bonding interactions, while two pairs of water dimmer filling in each hole. The $\mathrm{O} \cdots \mathrm{O} \cdots \mathrm{O}$ angles range from $125-174.8^{\circ}$, considerably deviating from the preferred ideal tetrahedral geometry of water. Meanwhile, there are infinite parallel aromatic rings from the phen, the $\pi-\pi$ stacking interactions also play an important role in stabilizing the supramolecular architecture (Fig. 4).

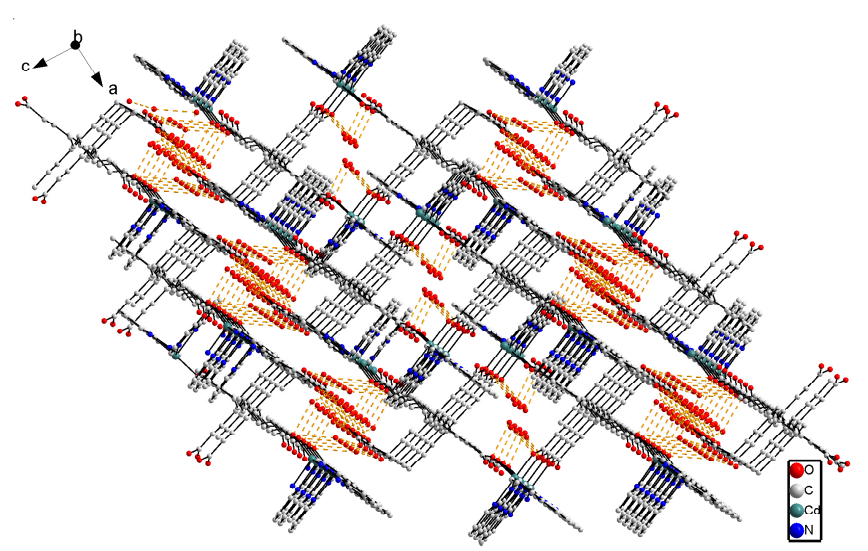

Fig. 4. Packing plot of $\mathrm{Cd}(\mathrm{II})$ complex

TG analysis: Thermal stability of the complex $\mathbf{1}$ was conducted under air atmosphere in the temprerature range of 30-800 ${ }^{\circ} \mathrm{C}$ with a $10{ }^{\circ} \mathrm{C} \mathrm{min}^{-1}$ ramp (Fig. 5). The TG diagram reveals two distinct weight regions. The first weight loss of $7.30 \%$ (calcd. $7.48 \%$ ) from $50-91{ }^{\circ} \mathrm{C}$ corresponds to the release of six water molecules. The further decomposition of the organic ligands occurred in the range of $170-480{ }^{\circ} \mathrm{C}$, the residue weights $17.64 \%$ corresponds to values calculated for $\mathrm{CdO} 17.66 \%$.

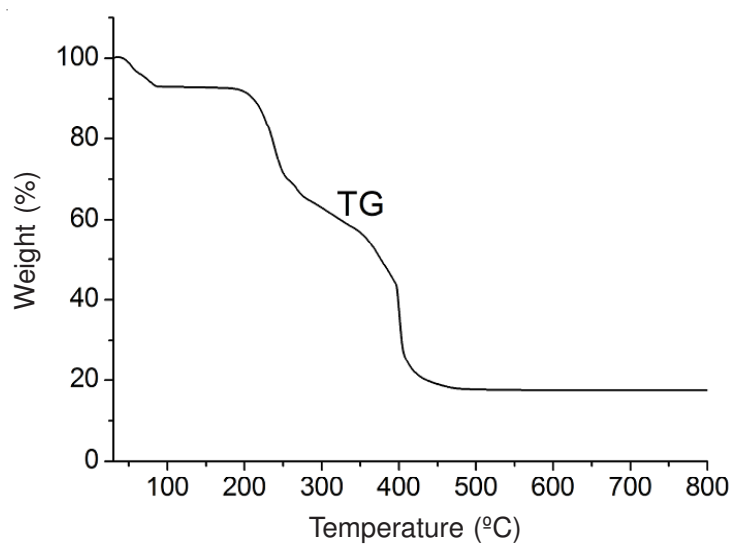

Fig. 5. TG curve for $\mathrm{Cd}(\mathrm{II})$ complex

Fluorescent property: Considering the introduction of $\mathrm{d}^{10}$ metal polynuclear clusters can improve the luminescent performance of coordination polymers, which have potential applications in chemical sensors, photochemistry and lightemitting diodes (LEDs) $)^{25-26}$. As depicted in Fig. 6, complex exhibit fluorescent emission with the maxima at $501 \mathrm{~nm}\left(\lambda_{\text {ex }}\right.$ $=358 \mathrm{~nm}$ ). Such fluorescence behaviour may be attributed to the intraligand transition of coordinated L ligand, since similar emission at $468 \mathrm{~nm}\left(\lambda_{\mathrm{ex}}=322 \mathrm{~nm}\right)$ was observed for the free L ligand. The red-shifted emissions of complex was attributed to both the deprotonated effect of $\mathrm{H}_{2} \mathrm{~L}$ and the coordination interactions of the organic ligands to the metal ${ }^{27}$. Which show that the complex may be excellent candidate for potential photoactive material. 
TABLE-3

HYDROGEN BOND GEOMETRY FOR TITLE COMPLEX $\left(\mathrm{nm},{ }^{\circ}\right)$

\begin{tabular}{lcccc}
\hline \multicolumn{1}{c}{ D-H $\cdots \mathrm{A}$} & $\mathrm{d}(\mathrm{D}-\mathrm{H})$ & $\mathrm{d}(\mathrm{H} \cdots \mathrm{A})$ & $\mathrm{d}(\mathrm{D} \cdots \mathrm{A})$ & $\angle$ (DHA) \\
\hline $\mathrm{O}(1 \mathrm{~W})-\mathrm{H}(1 \mathrm{WA}) \ldots \mathrm{O}(4)$ & 0.085 & 0.234 & $0.2948(10)$ & 129.3 \\
$\mathrm{O}(1 \mathrm{~W})-\mathrm{H}(1 \mathrm{WA}) \ldots \mathrm{O}(5 \mathrm{~W})$ & 0.085 & 0.271 & $0.3316(10)$ & 129.1 \\
$\mathrm{O}(2 \mathrm{~W})-\mathrm{H}(2 \mathrm{WB}) \ldots \mathrm{O}(5)$ & 0.085 & 0.200 & $0.2852(5)$ & 174.8 \\
$\mathrm{O}(3 \mathrm{~W})-\mathrm{H}(3 \mathrm{WA}) \ldots \mathrm{O}(7)$ & 0.083 & 0.197 & $0.2766(6)$ & 160.1 \\
$\mathrm{O}(3 \mathrm{~W})-\mathrm{H}(3 \mathrm{WB}) \ldots \mathrm{O}(7)^{\mathrm{a}}$ & 0.082 & 0.193 & $0.2726(6)$ & 162.2 \\
$\mathrm{O}(5 \mathrm{~W})-\mathrm{H}(5 \mathrm{WB}) \ldots \mathrm{O}(3 \mathrm{~W})^{\mathrm{b}}$ & 0.085 & 0.203 & $0.2612(8)$ & 125.0 \\
\hline
\end{tabular}

Symmetry codes: (a) $-\mathrm{x}+4,-\mathrm{y}+1,-\mathrm{z}$; (b) $\mathrm{x}-1, \mathrm{y}+1, \mathrm{z}+1$.

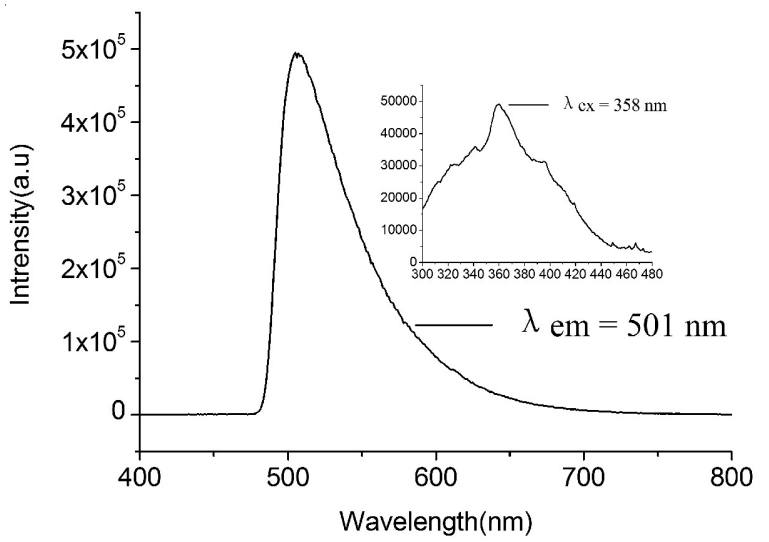

(a)

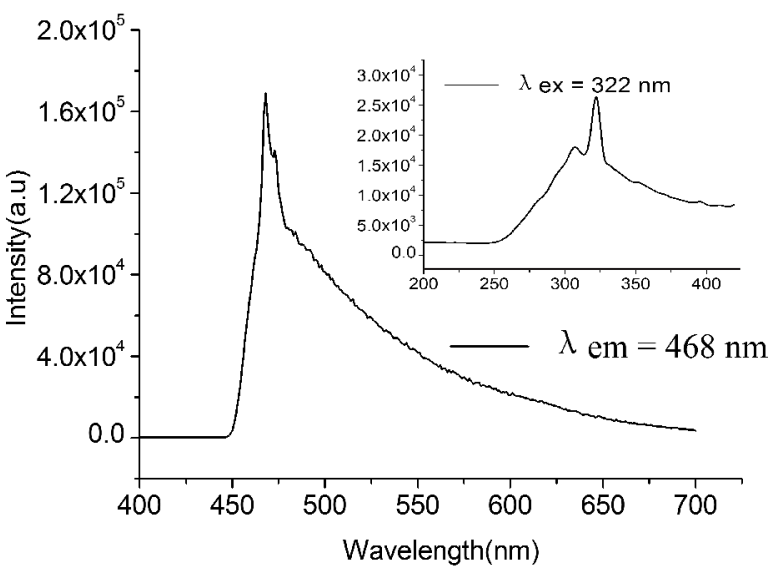

(b)

Fig. 6. Excitation and emission spectra in the solid state at room temperature: (a) the title complex (b) the $\mathrm{H}_{2} \mathrm{~L}$ ligand

\section{REFERENCES}

1. S. Kitagawa, R. Kitaura and S.I. Noro, Angew. Chem. Int. Ed., 43, 2334 (2004).

2. C.T. Chen and K.S. Suslick, Coord. Chem. Rev., 128, 293 (1993).

3. O. Kahn, Molecular Magnetism. New York: VCH Publishers (1993).

4. K. Nakatani, P. Bergeral and E. Codjovi, Inorg. Chem., 30, 3977 (1991).

5. R. Kumar, V.B. Taxak, Dayawati and S.P. Khatkar, Asian J. Chem., 26, (2014) (In press).

6. M. Fujita, Y.J. Kwon, S. Washizu and K. Ogura, J. Am. Chem. Soc., 116, 1151 (1994).

7. M. Fujita, Y.J. Kwon, O. Sasaki, K. Yaguchi and K. Ogura, J. Am. Chem. Soc., 117, 7287 (1995).

8. S.R. Batten, B.F. Hoskins, B. Moubaraki, K.S. Murray and R. Robson, Chem. Commun., 13, 1095 (2000).

9. O.R. Evans, R.G. Xiong and Z.Y. Wang, Angew. Chem. Int. Ed., 38, 4 (1999).

10. M.L. Tong, Y.M. Wu, J. Ru, X.-M. Chen, H.-C. Chang and S. Kitagawa, Inorg. Chem., 41, 4846 (2002).

11. L. Carlucci, G. Ciani, D.W. Gudenberg and D.M. Proserpio, Inorg. Chem., 36, 3812 (1997).

12. Y. Cui, H.L. Ngo and W.B. Lin, Chem. Commun., 1388 (2003).

13. L. Carlucci, G. Ciani and D.M. Proserpio, Cryst. Growth Des., 5, 37 (2005).

14. M. Seitz and A. Kaiser, J. Am. Chem. Soc., 126, 11426 (2004).

15. C.L. Chen, C.Y. Su, Y. P. Cai, H.-X. Zhang, A.-W. Xu, B.-S. Kang and H.-C. zur Loye, Inorg. Chem., 42, 3738 (2003).

16. H.D. Xian, J.F. Liu and G.L. Zhao, Sci. China Chem., 53, 2539 (2010).

17. G.L. Zhao, J.B. Shen and H.D. Xian, Sci. China Chem., 42, 983 (2012).

18. H.D. Xian, H.Q. Li, X. Shi, J.-F. Liu and G.-L. Zhao, Inorg. Chem. Commun., 12, 177 (2009).

19. M. Li, J.F. Xiang, L.J. Yuan, S.M. Wu, S.P. Chen and J.T. Sun, Cryst. Growth Des., 6, 2034 (2006).

20. S.L. Zheng, J.H. Yang, X.L. Yu, X.-M. Chen and W.-T. Wong, Inorg. Chem., 43, 830 (2004).

21. X.L. Wang, C. Qin, E.B. Wang, Y.G. Li, N. Hao, C.W. Hu and L. Xu, Inorg. Chem., 43, 1850 (2004).

22. G.M. Sheldrick, SHELXS-97, Program for the Solution of Crystal Structures, University of Göttingen, Germany (1997).

23. G.M. Sheldrick, SHELXL-97, Program for the Refinement of Crystal Structures, University of Göttingen, Germany (1997).

24. X. Nie, J.N. Qu and M.S. Chen, Chin. J. Inorg. Chem., 27, 2267 (2011).

25. M. Altmann and U.H.F. Bunz, Angew. Chem., 34, 569 (1995).

26. J.E. McGarrah, Y.J. Kim, M. Hissler and R. Eisenberg, Inorg. Chem., 40, 4510 (2001).

27. F.F. Li, J.F. Ma, S.Y. Song, J. Yang, Y.-Y. Liu and Z.-M. Su, Inorg. Chem., 44, 9374 (2005) 